\title{
Study of the Differences Between Government and Bank in Bank Loans: Evidence from Chinese Listed SMEs*
}

\author{
Yuliang Zhou \\ School of Finance \\ Guangdong University of Finance \& Economics \\ Guangzhou, China 510320
}

\author{
Haizhu Zhao \\ School of Finance \\ Guangdong University of Finance \& Economics \\ Guangzhou, China 510320
}

\author{
Xinyan Xie X* $^{*}$ \\ School of Humanities and Communication \\ Guangdong University of Finance \& Economics \\ Guangzhou, China 510320 \\ ***Corresponding Author
}

\begin{abstract}
Shenzhen SMEs board in China are taken as samples, and questionnaires and interviews methods are employed in this paper. First, the OLS models are established to analyses the impacts of firmgovernment relationship (FGR) and firm-bank relationship (FBR) on bank loan rates, loan costs, loan terms and loan default rates of SMEs. Then a Logit model is established to explore the substitution effect of loan structure of SMEs between FGR and FBR. The research results show that both FGR and FBR can effectively optimize the loan structures of SMEs under the atmosphere of Chinese social network relationship, but the role of government is obviously stronger than bank, and the FGR has the substitution effect on FBR.
\end{abstract}

Keywords-firm-government relationship (FGR); firm-bank relationship (FBR); bank loans

\section{INTRODUCTION}

As is known to all, guanxi is important social relationship in Chinese society, and problems are easily solved based on it. Granovetter (1973) defined social networks as connection composed of social relationships. Two ends of the connection are connection nodes, and the collection of different connection nodes with or without various contacts constitutes the social networks, including the interrelations of firms, banks, governments and other institutions. Furthermore, social networks are complex networked systems and have different resource possession and allocation (Brass, 2004). Conclusively, connection nodes of social networks related to SMEs' bank loans contain two primary types of social network relationships: the

*Fund: (1) The 13th five-year plan of Guangzhou philosophy and social science: "Research on the applicability of relationship loan in technological SMEs". (No. 2018GZQN38) (2) University youth innovational talent projects in Guangdong: "Enterprise' technology innovation: perspective of legality". (No. 2017WQNCX051) relationships between SMEs and governments and banks, namely firm-government relationship (FGR) and firm-bank relationship (FBR).

Granovetter \& Swedberg (1992) made further efforts to categorize embeddedness into relational embeddedness and structural embeddedness. It reflects that the economic activities are embedded in these two forms of social networks, of which the relational embeddedness emphasizes personal relationships and emotional communication. Additionally, to behavior subjects, the personal relationship factor plays an important role in making economic decisions. Structural embeddedness puts stress on the relationship between organizations or institutions instead of "face to face" relationship between individuals. Economic activities are embedded in the agency institutions, and dialogues between behavior subjects are carried out in their respective organizations. The formation and development of FGR is maintained by guanxi, renqing, such as blood relationship, popularity relation. Therefore in this study we argue that FGR belongs to relational embeddedness network, and this type of network mainly embodies in relatives and friends relations between SMEs and government. This suggestion is in line with Uzzi \& Gillesple (2002), while they claimed that FBR belongs to structural embeddedness network.

The purpose of this paper is to explore the difference of the role of the government and bank in bank loans of SME, which is embodied in the differences of bank loan rate, loan cost, loan term and loan default rate.

\section{DATE AND VARIABLES}

\section{A. Sample and Data}

Our sample begins with part of the SMEs listed on in Shenzhen Stock Exchange before the deadline of March 
2017. We discard the following two kinds: (1) Financial firms. Financial firms' capital and debt structure are not consistent with other SMEs', so it does not conform to conventional research. (2) ST, PT firms, and those firms with insufficient financial data or data exception. The left two hundred firms with normal financial data are selected. All these financial data are chosen from the widely-used CSMAR and RESSET.

Additionally, the related data of social networks are obtained through questionnaires and interviews. E-mails, field visits, phone calls and letters methods are employed to gain insight into whether SMEs have the FGR and FBR, and to obtain the subject numbers as well as other data. Our investigations are divided into two phases: the first phase is carried out from early July 2015 to the end of November 2015. Respondents are mainly the listed firms in Guangdong province, Zhejiang province, Jiangsu province, Beijing, Shanghai, etc. the eastern regions of China. Finally, 244 valid questionnaires are received. The second phase is carried out from July 2016 to December 2016. We reinvestigate the data in the first phase and replenish part of firms' data. Therefore, our final sample includes 389 groups of valid data of social network relationships.

\section{B. Variable Measurement}

Loan rate, loan cost and loan term related to bank loans, are designed as the main explained variables. These variables also frequently appear in other literatures, they can fully reflect SMEs' bank loan structures. Those three variables can be calculated by using firms' financial data. While the default rate is valued by on dummy variable.

We definite two types of SNR variables, namely the FGR and FBR as partial explaining variables. We refer to some literatures about the definition and measurement of political relationship. More specifically, whether there are senior government officials, congress members or ones closely associated with senior officials and party in firms' senior managers (Goldman et al., 2008; Goldman et al., 2009). If there are current or former government officials, NPC deputies and CPPCC members in firms' manage layer, we hold that SMEs have FGR; Similarly, if there are current or former managers holding posts in banks or other financial institutions, we think that SMEs have FBR. Both FGR and FBR are regarded as the dummy variables in this paper, we give value assignment of 0-1 binary variable, namely SMEs have the FGR and FBR, assign value 1; If not, assign value 0.

We also give some valuable control variables, explaining variables are constituted by the above relationship variables and the related control variables.

All variables, symbols and measure methods are defined as shown in "Table I".

TABLE I. VARIABLES MEASUREMENT AND EXPLANATION

\begin{tabular}{|c|c|c|c|}
\hline $\begin{array}{l}\text { Variables } \\
\text { types }\end{array}$ & Title & Symbol & Measure methods and explanations \\
\hline \multirow{4}{*}{$\begin{array}{l}\text { Explained } \\
\text { variables }\end{array}$} & Loan rates & Rate & Total loans/ total liabilities \\
\hline & Loan costs & Cost & Interest expenses/ total loans \\
\hline & Loan terms & Term & Long-term loans/ total loans \\
\hline & Loan default rates & Default & $\begin{array}{l}\text { Last year's short-term loans (including the long-term loans within the maturity) }- \text { the } \\
\text { current loans to be repaid: }>0 \text {, Repayment procrastination, namely default, assign value } 1 \text {; } \\
\leqq 0 \text {, assign value } 0\end{array}$ \\
\hline \multirow{2}{*}{$\begin{array}{l}\text { Explaining } \\
\text { variables }\end{array}$} & $\begin{array}{l}\text { Firm-government } \\
\text { relationship }\end{array}$ & FGR & $\begin{array}{l}\text { Dummy variables: current or former government officials, NPC deputies or CPPCC } \\
\text { members among firm managers, assign value } 1 \text {; conversely, assign value } 0\end{array}$ \\
\hline & Firm-bank relationship & FBR & $\begin{array}{l}\text { Dummy variables: current or former staffs working in banks among firm managers, assign } \\
\text { value } 1 \text {; conversely, assign value } 0\end{array}$ \\
\hline \multirow{7}{*}{$\begin{array}{l}\text { Explaining } \\
\text { variables } \\
\text { (controlled } \\
\text { variables) }\end{array}$} & Firm scale & Size & Natural logarithm of total corporate assets, signifies production size \\
\hline & Growth capability & Growth & Operating revenues / last year's operating revenues -1 \\
\hline & Profit capability & Profit & Firms' net assets yield \\
\hline & Current capital & Capital & Natural logarithm of firms' current capital, signifies anti-risk capability and liquidity \\
\hline & Firm age & Age & 2016-firms' registration date \\
\hline & Industry types & Industry & $\begin{array}{l}\text { Dummy variables: manufacturing industry }(\mathrm{C}) \text {, assign value } 1 \text {; other industries, assign } \\
\text { value } 0\end{array}$ \\
\hline & Network scope & Scope & Quantity of related contact nodes with SMEs \\
\hline
\end{tabular}

\section{ANALYSIS AND RESULTS}

\section{A. Substitution Effects of FGR and FBR on Loan Structure}

We set OLS regression equation with cross-multiply items to test $H_{1}$. We compare the substitution effects of FGR with FBR on bank loan rate, loan cost, loan term.

Loan $=\alpha+\beta_{1} F G R+\beta_{2} F B R * F G R+\beta_{3} F B R *(1-F G R)+\gamma C+\varepsilon$
In the formula (1), $\alpha$ is the constant term, $\beta$ and $\gamma$ are the coefficients of two kinds of network relationship variables and series control variables respectively, $\mathcal{E}$ is the error term. According to the measurement of each variable in "Table I", we carry out a OLS regression with the data of sample firms. And the heteroscedasticity correction technology is employed in this paper to solve the problem of heteroscedasticity. Meantime, we carry out a correlation analysis on the SNR variables and find the correlation among two variables is not strong basically, the correlation 
coefficients between the variables are low.Then the step-wise regression is used, but there are no variables excluded, the results show there are no multicollinearity among the SNR variables.

The coefficients of cross-multiply items, such as $F B R^{*} F G R, \quad F B R^{*}(1-F G R)$ are designed to judge the substitution effects of FGR and FBR of SMEs on bank loans. If there is no FGR, the formula (1) will be changed as follows:

$$
\text { Loan }=\alpha+\beta_{3} F B R+\gamma C+\varepsilon
$$

If SMEs have FGR, the formula (2) will be changed as follows:

$$
\text { Loan }=\alpha+\beta_{1}+\beta_{2} F B R+\gamma C+\varepsilon
$$

Additionally, if formula (2) is equivalent with formula (3), we can get that coefficient of $\beta_{2}$ is less than the coefficient of $\beta_{3}$. It means that the effect of FBR on bank loans will be weakened, namely the SMEs with FGR have less dependence on FBR than those without FGR in bank loans. Regression results are shown in the "Table II".

TABLE II. REGRESSION RESULTS OF SUBSTITUTION EFFECTS OF FGR

\begin{tabular}{|c|c|c|c|}
\hline & Rate & Cost & Term \\
\hline Intercept & $\begin{array}{l}0.288^{* * *} \\
(0.746)\end{array}$ & $\begin{array}{l}0.213 * * \\
(0.553)\end{array}$ & $\begin{array}{l}0.169^{*} \\
(0.482)\end{array}$ \\
\hline FGR & $\begin{array}{l}0.163^{*} \\
(0.456) \\
\end{array}$ & $\begin{array}{l}-0.224 * * \\
(-0.240)\end{array}$ & $\begin{array}{l}0.077^{*} \\
(0.296)\end{array}$ \\
\hline FBR*FGR & $\begin{array}{l}0.060^{*} \\
(0.199)\end{array}$ & $\begin{array}{l}-0.113^{*} \\
(-0.370)\end{array}$ & $\begin{array}{l}0.039^{*} \\
(0.105)\end{array}$ \\
\hline $\begin{array}{ll}\text { FBR }^{*}(1 & - \\
\text { FGR }) & \\
\end{array}$ & $\begin{array}{l}0.088 * * \\
(0.146)\end{array}$ & $\begin{array}{l}-0.196^{*} \\
(-0.587)\end{array}$ & $\begin{array}{l}0.076^{*} \\
(0.234)\end{array}$ \\
\hline Adj. R2 & 0.277 & 0.201 & 0.102 \\
\hline F-statistic & $11.004 * * *$ & 8.637 *** & $4.965 * * *$ \\
\hline
\end{tabular}
ON FBR

a. Notes: *,** and $* * *$ respectively represents statistical significance at $10 \%, 5 \%$ and $1 \%$ level, standard errors are shown in brackets. STATA software indicates R2 and F - statistic.

In "Table II", by comparing the regression coefficient of FGR with the cross-multiply items coefficients of FBR, we find that the cross-multiply items coefficients of FBR* $(1-$ FGR) pass the test of significance. Furthermore, the absolute value of those coefficients are greater than the coefficients of FBR* FGR respectively. According to the theory meaning of set models, we argue that the SMEs without FGR will be more dependent on the trust mechanism generated by FBR in bank loans; However, the SMEs with FGR will weakened the dependence on FBR. It can be fully proved from the comparison of FGR and the coefficients of FBR* FGR in the corresponding equations.

By making a comparison of the substitution effects of FGR and FBR, we find that most of the conclusions can confirm hypotheses $H_{1}$. SMEs may encounter difficulties in obtaining superior loan resources without FGR, even though through FBR. However, FBR would be SMEs' preferred option to get bank loans if there was no FGR.

\section{B. Comparison of Effects of FGR and FBR on Default Rate}

As to hypothese $\mathrm{H}_{2}$, since Default is a binary variable (01), Logit model between two SNR variables and SMEs' bank loan default rates is built, as shown in formula (4):

Logit $=\alpha+\beta_{1} \operatorname{Ln}(1+F G R)+\beta_{2} \operatorname{Ln}(1+F B R)+\gamma C+\varepsilon$

Results of regression analysis in the Logit model indicate that the regression equation pass the likelihood ratio (LR) test at $1 \%$ significance level, it proves the homoskedasticity hypothesis of the model is tenable. Regression results are shown in "Table III".

TABLE III. REGRESSION RESULTS OF LOGIT MODEL

\begin{tabular}{|l|l|l|}
\hline & $\mathrm{D} 1$ & $\mathrm{D} 2$ \\
\hline Intercept & $\begin{array}{l}2.449^{* *} \\
(2.004)\end{array}$ & $\begin{array}{l}2.185^{*} \\
(2.390)\end{array}$ \\
\hline Ln (1+FGR) & $\begin{array}{l}0.730^{* *} \\
(2.083)\end{array}$ & \\
\hline Ln (1+FBR) & & $\begin{array}{l}-0.475^{*} \\
(2.100)\end{array}$ \\
\hline Pseudo R2 & 0.243 & 0.122 \\
\hline IMR & $30.446^{* * *}$ & $27.962^{* * *}$ \\
\hline LR test & $\begin{array}{l}2.449^{* *} \\
(2.004)\end{array}$ & $\begin{array}{l}2.185^{*} \\
(2.390)\end{array}$ \\
\hline
\end{tabular}

a. Notes: Table III reveals the regression results of test on hypothesis $H_{3}$, among them, $\mathrm{D}_{1}$ and $\mathrm{D}_{2}$ represent loan default rate. The data in the chart below make a comparison of the effects of FGR and FBR on the loan default rates, it reflects the different effects of two types of networks on SMEs' bank loans.

"Table III" presents that FGR have significant positive effects on default rates at least at $10 \%$ significance level. That is to say, based on the trust mechanism generated by SMEs' social interpersonal relationships with governments, the bank loan default rates are higher. Whereas, FBR has significant negative effects on default rates at least at $10 \%$ significance level. It means that SMEs' trust mechanism generated by the relationships between SMEs and banks can reduce loan default rates. It also confirms that the trust mechanism based on organizations or institutions plays a much more important role in maintaining the stability of SMEs' loans than that based on individual "guanxi". Finally, we make a robustness analysis, the results show that the above empirical analysis have good stability.

\section{CONCLUSION}

Our findings provide the following implications: First, the strength of personal relationship of FGR is greater than the organizational relationship of FBR basically. It suggests that Chinese SMEs rely more on managers' social interpersonal relationship than the relationship between SMEs and banks. It differs greatly from the western social network. Therefore, Chinese SMEs' financing behavior should be embedded in China's national conditions and take targeted reform measures. Second, the bank loans obtained by FGR are less stable than that by FBR. It also illustrates that the restrictions and sanctions on repayment by personal trust mechanism are much weaker than that by organizational trust mechanism. As a result, the future development of SMEs' social networks should be apt to FBR or other structural embeddedness network relationships 
gradually, such as group loans, industrial clusters, industryuniversity-research cooperation and financing agencies cooperation.

\section{REFERENCES}

[1] D.J. Brass, Taking Stock of Networks and Organizations: A Multilevel Perspective, Academy of Management Journal. 47 (2004) 795-817.

[2] E. Goldman, J. Rocholl and J. So. Do Politically Connected Boards Affect Firm Value? Review of Financial Studies, 22 (2009) 23312360 .

[3] E. Goldman, J. So and J. Rocholl. Political Connections and the Allocation of Procurement Contracts, SSRN Working Paper. (2008) 965-888.

[4] M. Granovetter, The Strength of Weak Ties, American Journal of Sociology. 78 (1973) 1360-1380.

[5] M. Granovetter, R. Swedberg, The Sociology of Economic Life, West view Press. 1992.

[6] B. Uzzi, J.J. Gillespie. Knowledge Spillover in Corporate Financing Networks: Embeddedness and the Firms Debt Performance, Strategic Management Journal. 23 (2002) 595-618. 